\title{
Estágios imaturos de Actinote carycina Jordan (Lepidoptera, Nymphalidae, acraeinae) ${ }^{1}$
}

\author{
Márlon Paluch ${ }^{2,3}$ \\ Mirna M. Casagrande 2, 4 \\ Olaf H.H. Mielke ${ }^{2,4}$
}

\begin{abstract}
Immature stages of Actinote carycina Jordan (Lepidoptera, Nymphalidae, Acraeinae). Data on the life cycle and morphology of immature stages of Actinote carycina Jordan, 1913 are presented. The larvae feed on leaves of Eupatorium inulaefolium H.B.K. (Asteraceae).

KEY WORDS. Immature stages, biology, morphology, hostplant
\end{abstract}

Este é o segundo artigo que faz parte de uma série sobre a bionomia e morfologia dos imaturos de Actinote Hübner, [1819], visando contribuir para a resolução dos problemas taxonômicos a partir da reunião dos caracteres dos imaturos, como subsídios para a classificação do grupo, pois pouco se conhece a respeito da morfologia dos imaturos e dos aspectos etológicos e ecológicos (PALUCH et al. 1999).

Actinote carycina Jordan, 1913 é uma das espécies mais polimórficas do gênero, facilmente constatado pelas variações descritas por D'ALMEIDA (1935) e Mielke \& Casagrande (1986). Das dez espécies listadas para Curitiba e seus arredores por C. MiELKE (1994), A. carycina é uma das mais abundantes, sendo possível encontrá-la voando em novembro e meados de março.

\section{MATERIAL E MÉTODOS}

Os exemplares de Actinote carycina utilizados para este estudo são provenientes de Curitiba e arredores, 900-950 m; Rebouças, $815 \mathrm{~m}$ e Morro Alto, $350 \mathrm{~m}$ no município de Morretes na Serra do Mar, todas localidades situadas no Estado do Paraná, Brasil.

Ovos e larvas foram mantidos em placas de Petri e gaiolas de criação, juntamente com folhas e ramos da planta hospedeira; todos os estágios do ciclo evolutivo foram acompanhados e mantidos em casa de vegetação.

Exemplares de todas as fases do desenvolvimento foram fixados em líquido Dietrich e os adultos preparados em alfinetes e depositados na Coleção de Entomologia Pe. Jesus Santiago Moure, Departamento de Zoologia, Setor de Ciências Biológicas, Universidade Federal do Paraná, Curitiba, Paraná, Brasil.

1) Contribuição número 1289 do Departamento de Zoologia, Universidade Federal do Paraná.

2) Departamento de Zoologia, Universidade Federal do Paraná. Caixa Postal 19020, 81531-990 Curitiba, Paraná, Brasil.

3) Bolsista Mestrado do CNPq

4) Pesquisador do CNPq. 
Das plantas utilizadas para as posturas e posterior alimentação das larvas, foram preparadas exsicatas, identificadas e depositadas na coleção acima citada.

A interpretação da quetotaxia da larva de primeiro instar segue HinTON (1946) e STEHR (1987) e as áreas do corpo PETERSON (1962).

\section{Plantas hospedeiras, oviposição, ciclos e danos}

BIEZANKO et al. (1974) listam como plantas hospedeiras de A. carycina no Uruguai Eupatorium buniifolium Hook. et Arn.; E. hirsutum Hook. \& Arn.; E. inulaefolium H.B.K.; E. laevigatum Lam.; E. macrocephalus Less. e E. oblongifolium Bak. (Asteraceae, mencionado como Compositae)

Brown (1992) lista como planta hospedeira da espécie, na Serra do Japi, São Paulo, Brasil, Eupatorium gaudichaudianum ACS.

Todas as posturas encontradas estavam sobre folhas de Eupatorium inulaefolium H.B.K., onde foram mantidas durante todo o desenvolvimento larval até o empupamento.

Nos locais estudados A. carycina apresentou duas gerações ao ano, portanto bivoltina e sete ínstares larvais, estes com início em novembro/dezembro e março/abril. A geração descrita morfologicamente neste artigo refere-se a de novembro/março, assim como a duração em dias dos estágios imaturos.

D'ALMEIDA (1925) cita sete ínstares larvais para Actinote brasiliensis D'Almeida, 1922, um sinônimo de Actinote pyrrha (Fabricius, 1775) e com três gerações ao ano no Rio de Janeiro

As posturas são feitas na face abaxial da folha em grupos de 400 a 450 ovos, postos lado a lado, corroborando com a quantidade de ovos citados por ZIKÁN (1952).

As larvas apresentam comportamento semelhante a Actinote surima (Schaus, 1902) (PALUCH et al. 1999), utilizando o cório como primeira alimentação, possuem hábitos gregários e alimentam-se do parênquima das folhas, deixando as nervuras até atingirem o quinto instar. A partir do sexto instar são encontradas em grupos de três a cinco larvas, alimentando-se de toda a folha. As larvas de sétimo instar, em março, podem ser encontradas herbivorando os botões ou as flores da planta hospedeira, fato que não é constatado no final do ciclo outono/inverno, pois as florações de Asteraceae nas regiões estudadas são anuais.

Durante o inverno, em Rebouças uma das regiões estudadas, as larvas enfrentam condições extremas durante a chegada das geadas severas, quando a face adaxial da folha é coberta pelo gelo, as larvas alimentam-se, após o degelo, até o final da tarde, num período aproximado de cinco a seis horas diárias. Este comportamento também foi observado para Actinote surima (Schaus, 1902) (PALUCH et al. 1999).

Raramente as larvas empupam na planta hospedeira, preferindo a vegetação próxima às plantas hospedeiras. Os adultos são facilmente capturados no final do verão em flores de Asteraceae.

As condições da casa de vegetação em Curitiba durante o ciclo acompanhado entre novembro e abril foram as seguintes: temperatura média de $24,9^{\circ} \mathrm{C}$, com mínima de $13,5^{\circ} \mathrm{C}$ e máxima em $34^{\circ} \mathrm{C}$, a umidade relativa do ar teve a média de $67,6 \%$, com mínima de $44,5 \%$ e máxima em $100 \%$. 
Da postura até a eclosão dos ovos passaram-se 15 dias, da eclosão até à primeira ecdise 13 dias, da primeira à segunda ecdise 12 dias, da segunda à terceira ecdise 12 dias, da terceira à quarta ecdise 13 dias, da quarta à quinta ecdise 12 dias, da quinta à sexta ecdise 10 dias, da sexta para pupa 10 dias e de pupa para a emergência do imago 11 a 13 dias. O período total da geração novembro/março tem aproximadamente 110 dias.

\section{Morfologia externa dos imaturos}

\section{Ovo (Figs 1-3)}

Em forma de barril, com textura irregular. Eixo micropilar posicionado verticalmente ao plano do substrato, área micropilar lisa que, em contraste com o reticulado do restante do cório fornece a impressão, quando observada em vista dorsal, ser deprimida, porém encontra-se no mesmo plano.

Logo após a oviposição a coloração é amarelo leitosa, passando nos dias subsequentes ao róseo intenso. Aproximadamente 20 horas antes da eclosão das larvas, pela transparência do cório pode-se observar a larva de coloração clara rosada, com cabeça escura (Fig. 3).

Mensurações. Diâmetro $(n=22)$ : variando de 0,58 a $0,6 \mathrm{~mm}$. Altura $(n=$ 21): de 0,84 a $0,86 \mathrm{~mm}$.

\section{Larva de primeiro instar (Figs 4-11)}

Cabeça arredondada, lisa e sem escolos. Coloração geral castanho escura, com cerdas castanho claras. As cerdas longas e táteis (HINTON 1946; STEHR 1987), localizadas na face anterior da cabeça são facilmente identificáveis pelas fotos em microscopia eletrônica (Figs 4-5). Cerdas A1, A2 e A3 eqüidistantes e de mesmo tamanho, porém pouco menores que $\mathrm{P} 1$ e P2. AF1 e AF2 do mesmo tamanho. C1 e C2 têm a metade em tamanho do padrão A1, A2 e A3. L1 é a mais longa e mais afastada de todas. S1, S2 e S3 tão longas como C1 e C2. SS2 entre os estemas cinco e seis. SS1 e SS3 aproximadamente a metade do tamanho de SS2 e somente visualizadas em vista ventral (Fig. 5). No labro, três pares de Medianas (M1, M2 e M3) e três de Laterais (L1, L2 e L3) (Fig. 6). Microcerdas MD1, MD2 e MD3 presentes na região posterior à cerda $\mathrm{P} 2$. Entre $\mathrm{o}$ par de cerdas $\mathrm{F} 1$, na região ventral da fronte, encontra-se o ponto $\mathrm{Fa}$. Sobre o quarto estema está o ponto $\mathrm{Sb}$, menos perceptível está o ponto $\mathrm{Pb}$ próximo à base da cerda $\mathrm{P} 2 ; \mathrm{Pa}$ entre a cerda $\mathrm{A} 3$ e o segundo estema; Mda entre as microcerdas MD1 e MD2; Aa entre as cerdas A2 e A3 e acima do terceiro estema; La próximo à base da cerda L1; Sa entre o sexto estema e a cerda S2 e SSa abaixo do quinto estema. Área na base das maxilas revestida com estruturas salientes e de aspecto mamiformes (Fig. 7); é similar a apresentada por Actinote surima (Schaus, 1902) (PALUCH et al. 1999).

Corpo cilíndrico, branco leitoso, levemente rosado no tórax e nos primeiros segmentos do abdome devido substância desta cor presente no tubo digestivo que após a primeira alimentação, passa a ser esverdeada. Sem escolos, apenas cerdas castanho escuras (Fig. 11). Todas as cerdas partem de placas esclerotinizadas um pouco acima do plano do tegumento, exceto as duas subventrais de A3-A6 contidas na placa lateral do larvópodo, as quatro subventrais de A10 na placa lateral do larvópodo e as ventrais de A1, A2 e A10. T1 diferenciado pela presença da placa 

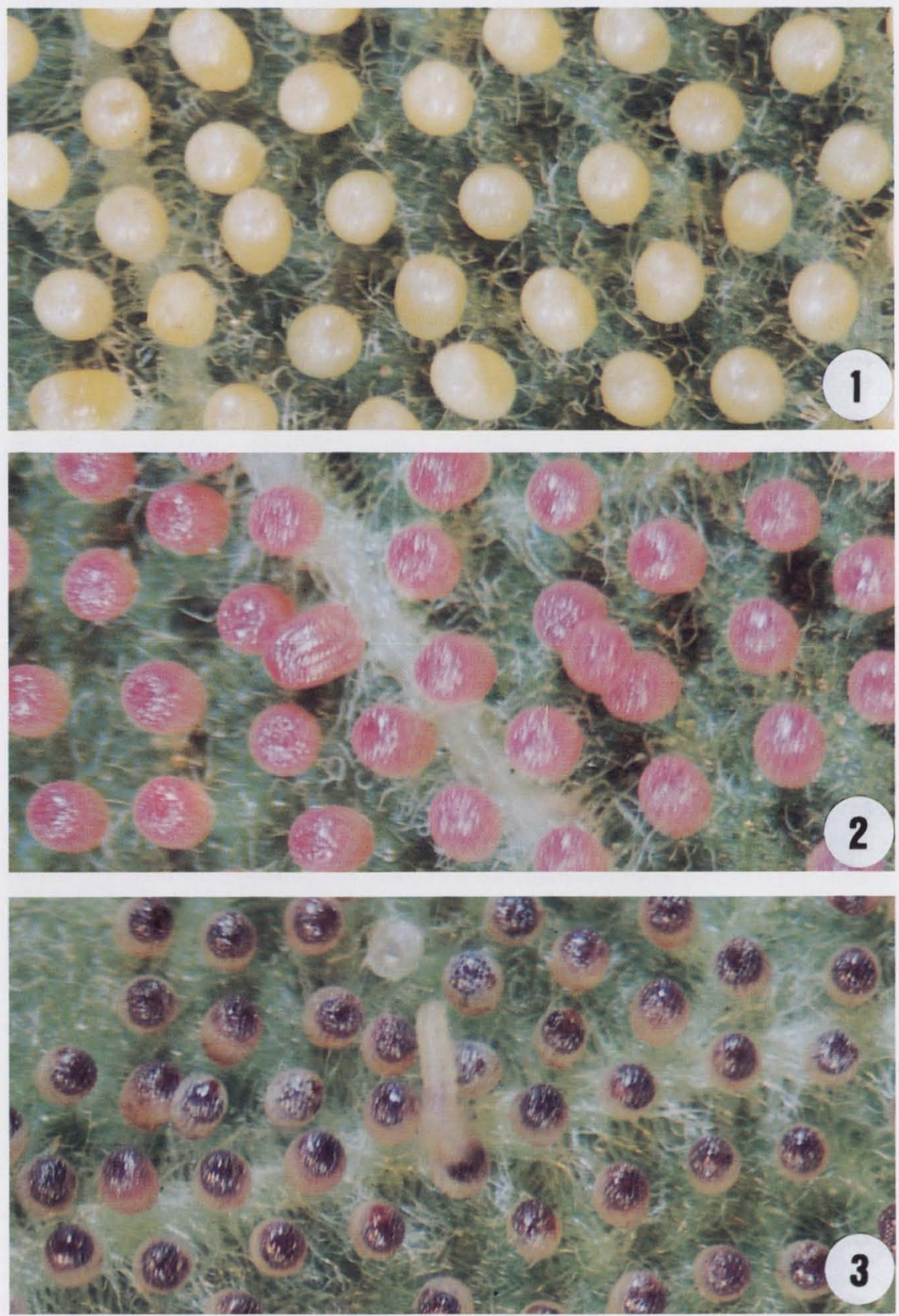

Figs 1-3. Actinote carycina, postura. (1) Logo após a oviposição; (2) seis dias após a oviposição; (3) ovos próximos da eclosão e larva recém emergida. 

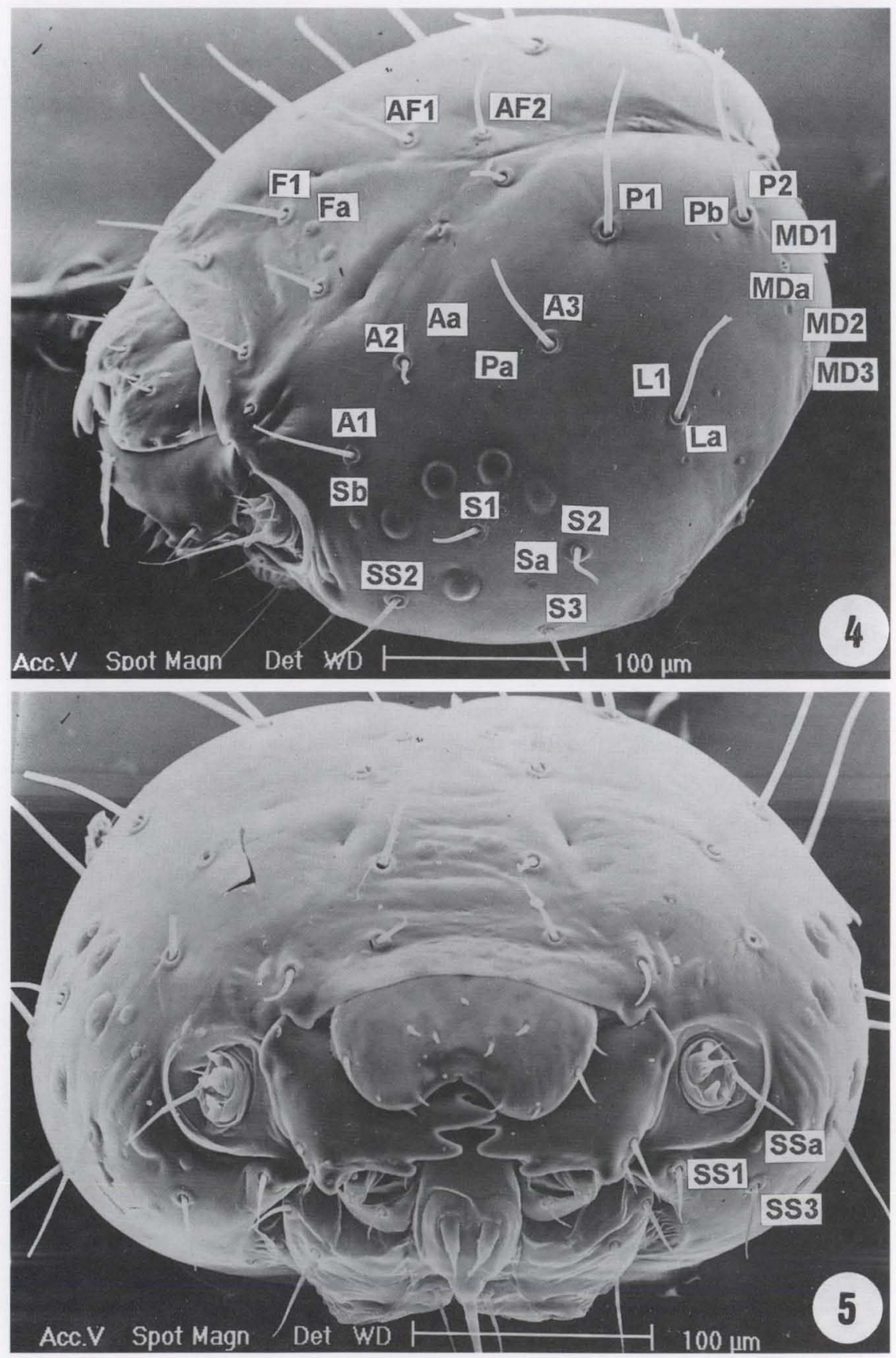

Figs 4-5. Actinote carycina, larva de primeiro instar, quetotaxia da cabeça. (4) Vista lateral; (5) vista ventral. 

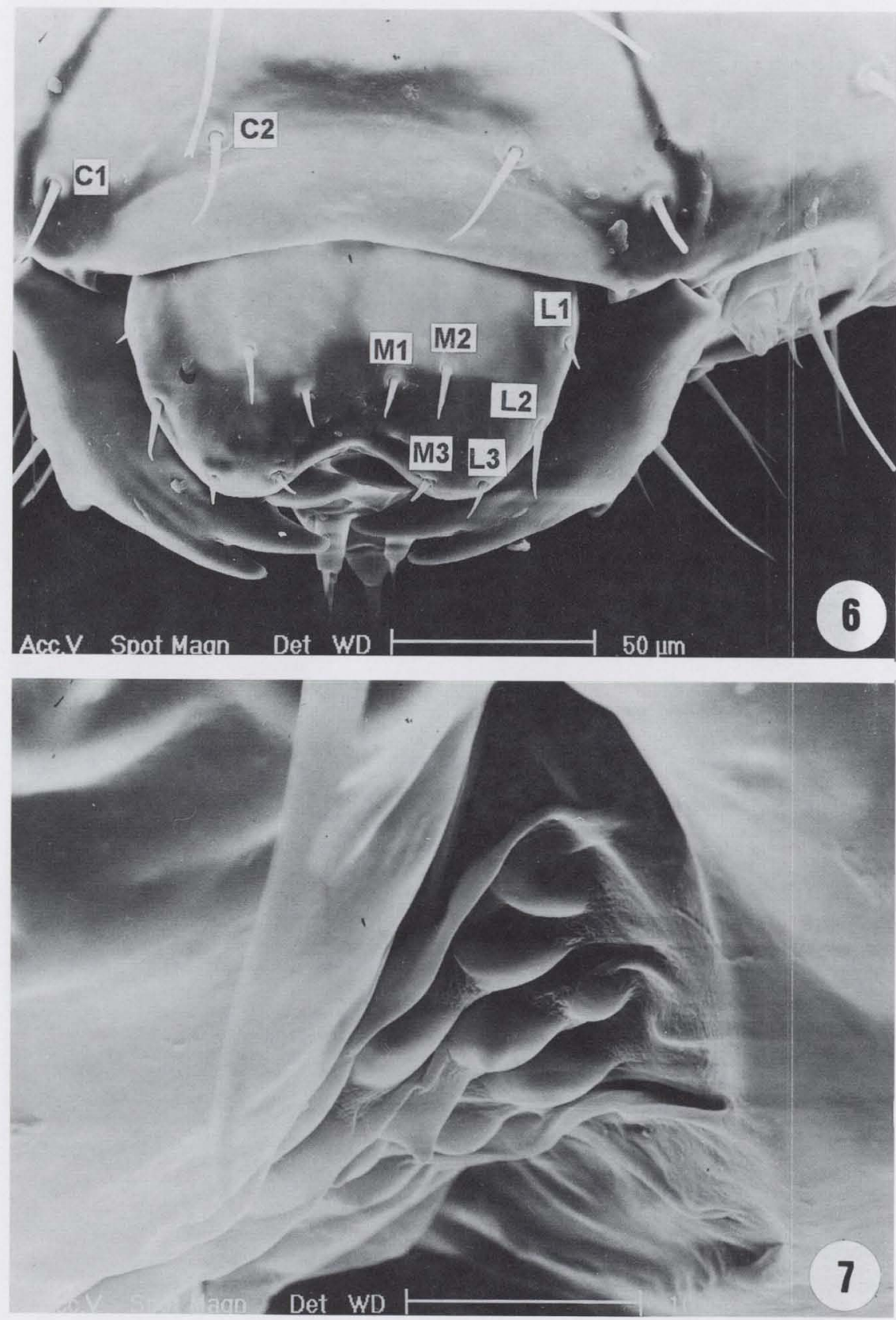

Figs 6-7. Actinote carycina, larva de primeiro instar, quetotaxia da cabeça. (6) Vista frontal com detalhes do anteclipeo, labro, mandibulas e antena; (7) vista inferior da base das maxilas com detalhe de estruturas mamiformes. 

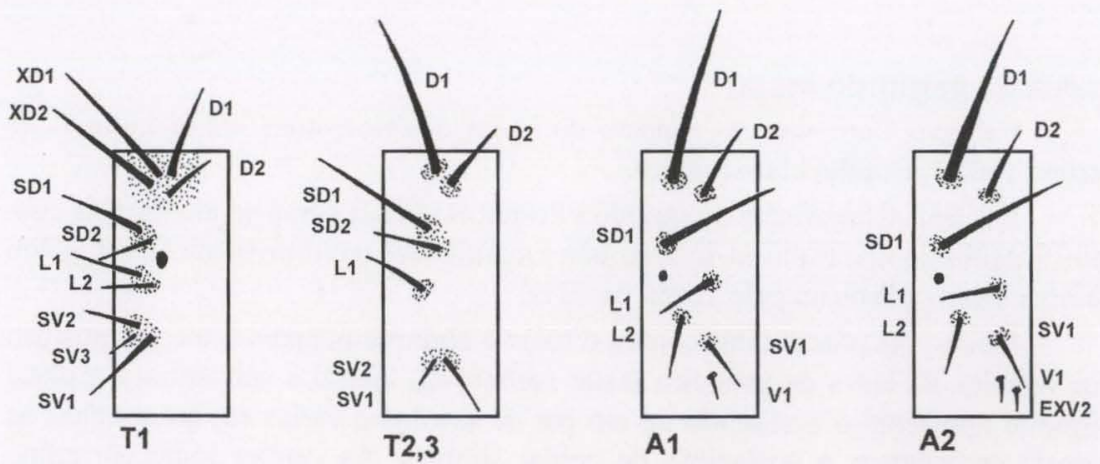

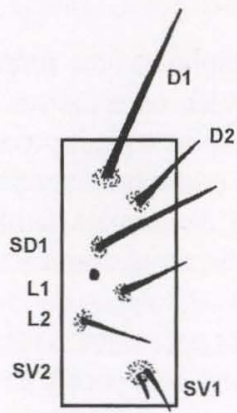

A3- 6

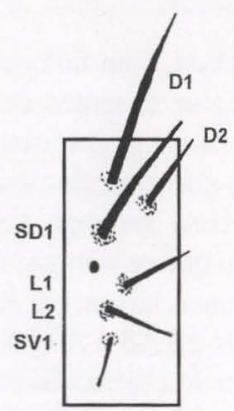

A7, 8

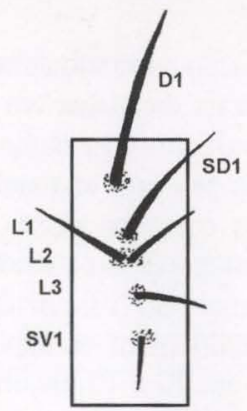

A9

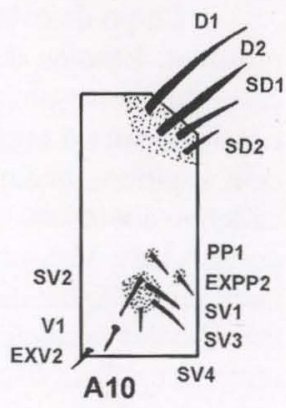

8
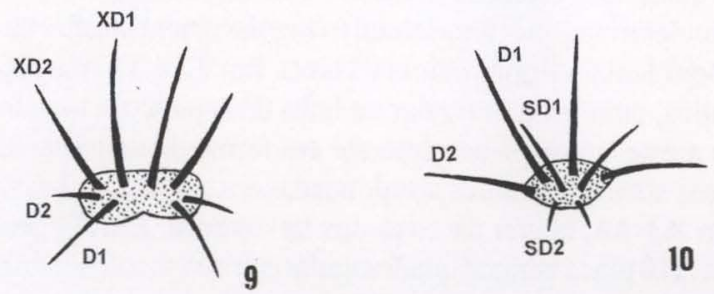

Figs 8-10. Actinote carycina, larva de primeiro instar, quetotaxia do corpo. (8) Segmentos do tórax e abdome; (9) placa pronotal; (10) placa suranal.

pronotal, L2 e SV3; ausentes em T2 e T3. Apenas o segmento A9 apresenta L3, sendo que em alguns casos L2 pode estar ausente neste segmento. Em A1 uma cerda do grupo ventral, V1; em A2 e A10 duas cerdas V1 e "EXV2". A cerda SD2 está ausente nos segmentos abdominais A1 até A9, aparecendo somente em T1-T3 e A10. SV1, SV2 e SV3 presente em T1; SV1 e SV2 em T2, T3 e na lateral dos larvópodos de A3-A6; SV1 em A1, A2 e A7-A9 e SV1, SV2, SV3, SV4 em A10 na placa lateral do larvópodo, PP1 e "EXPP2" em A10 no paraprocto (Figs 8-10).

Mensurações da cápsula cefálica representadas pela escala nas eletromicrografias de varredura. Comprimento total $(n=13)$ : variando de 0,352 a $0,36 \mathrm{~cm}$. 


\section{Larva de segundo instar}

Cabeça. Com mesmo aspecto do instar anterior, com maior número de cerdas, todas castanho claro hialino.

Escolos. Classificados segundo PETERSON (1962) como sendo escolos com ramificações do tipo espinho. Este padrão é mantido até o último instar larval, assim como a sua distribuição pelo corpo da larva.

Placas. As placas citadas para o tórax e abdome ocupam a mesma posição que aquelas da larva de primeiro instar (subdorsal, lateral e subventral), a placa pronotal apresenta o acréscimo de um par de escolos e várias cerdas simples, as demais apresentam o acréscimo de cerdas simples. As cerdas aparecem como caracteres secundários, variando em número e posição a partir deste instar, sendo que em uma mesma larva pode ocorrer variação de cerdas nas placas tornando-as assimétricas.

Corpo de coloração castanho amarelada, com faixa castanha na área supraespiracular. Escolos dorsais dispostos em linha, ausentes em A10, os torácicos são castanhos com espinhos hialinos castanho claros e o protorácico sobre a placa pronotal é voltado para a região anterior, enquanto que os abdominais castanho-amarelados com espinhos hialinos castanho claros. Uma segunda linha de escolos também castanho amarelados, menores em tamanho que os dorsais, na área supraespiracular, desde $\mathrm{A} 1$ até $\mathrm{A} 10$, ausentes em A9. Em algumas larvas, em A 10 a coloração do escolo pode ser castanha; quando assim, os dorsais em A8 e A9 podem apresentar a mesma cor. Escolos presentes em T2 e T3, na linha do espiráculo protorácico, porém em T2 um pouco acima. Abaixo dos espiráculos e caudais em relação a estes, estão os escolos subespiraculares, presentes de A 1-A8. Os escolos dorsais, supraespiraculares e subespiraculares possuem espinhos hialinos castanho-claros. Em T1 três placas, uma supraespiracular triangular, uma lateral triangular abaixo desta e na frente do espiráculo e uma subespiracular elíptica acima da coxa. Em T2 e T3 três placas, uma supraespiracular elíptica, uma lateral circular na linha do espiráculo torácico e com o diâmetro semelhante a este, e uma subespiracular em forma de meia-lua acima das coxas. Em A 1-A9 placas subespiraculares arredondadas em A1, A2, A7-A9, e elípticas e menos distintas em A3-A6, acima da coxa dos larvópodos. Em A9 placa supraespiracular eliptica. Em A 10 placa suranal quadrangular entre os escolos, e na região do paraprocto duas placas que em alguns casos podem se fundir, formando uma única semicircular. Todas as placas do corpo apresentam a cor castanho claro com cerdas hialinas ou castanho claras hialinas variando em número e posição.

Ventralmente entre a cabeça e o primeiro par de pernas está presente a glândula jugular, eversível PETERSON (1962), representada por uma dobra no tegumento em direção às peças bucais quando em repouso.

Envolvendo cada uma das coxas torácicas uma placa castanha, com forma de ferradura, cuja abertura é voltada látero ventralmente com várias cerdas claras. As pernas torácicas castanhas com cerdas hialinas; o trocanter como um estreito anel; fêmur, tíbia, tarso e garras tarsais distintos.

As laterais dos larvópodos possuem várias cerdas hialinas sobre as placas dos larvópodos, mais evidentes no larvópodo anal por apresentar a placa castanho claro. 

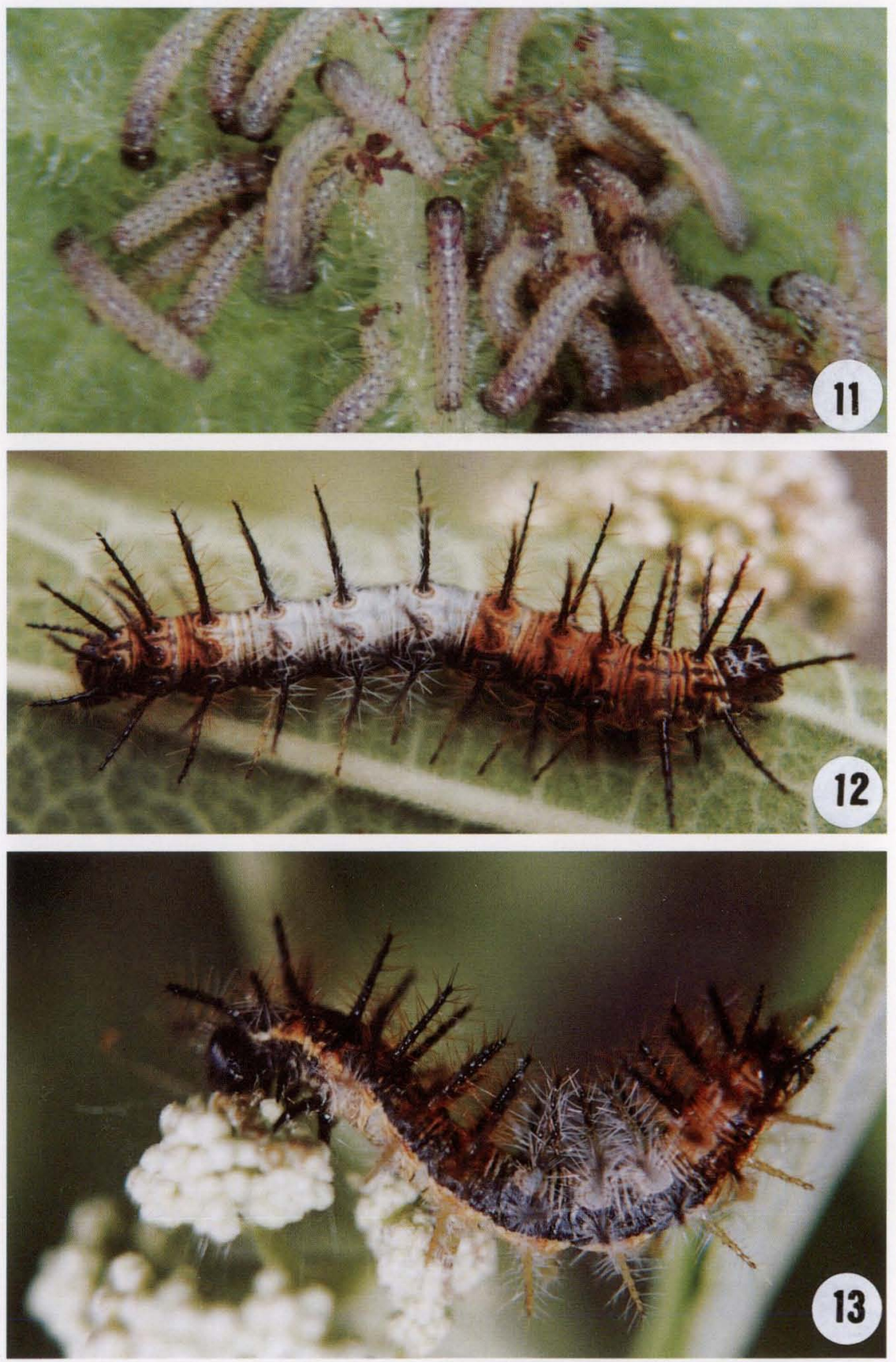

Figs 11-13. Actinote carycina, larvas. (11) Primeiro instar recém eclodidas; (12) sétimo instar, vista dorsal; (13) sétimo instar, vista lateral, alimentando-se dos botões de flores de $E$. inulaefolium. 
Espiráculos abdominais circulares e menores que o torácico, com exceção do oitavo par que é semelhante.

O tegumento do tórax e do abdome nas áreas dorsal, subdorsal, subespiracular e ventral apresenta-se castanho amarelado. Área supraespiracular ornamentada por faixa castanha. Pequenas cerdas claras estão distribuídas por todo o corpo.

Mensurações. Largura da cápsula cefálica, obtida através da distância entre os lados externos do terceiro par de estemas $(n=28)$ : variando de 0,56 a $0,64 \mathrm{~mm}$. Comprimento total $(\mathrm{n}=8)$ : variando de 0,43 a $0,48 \mathrm{~cm}$.

\section{Larva de terceiro instar}

Cabeça. Com mesmo padrão e coloração que o instar anterior.

Corpo. As larvas mais escuras, de castanho mais intenso, apresentam todos os escolos do tórax, além dos dorsais e supraespiraculares de A1, A2 e A7-A10, castanhos com espinhos castanho claros, os demais escolos castanho amarelados com espinhos hialinos castanho claros.

As larvas mais claras apresentam apenas o escolo dorsal de T1 castanho com espinhos castanho claros, os demais são castanho amarelados com espinhos hialinos castanho claros. Além destes há outros padrões intermediários de coloração. Placas pronotal e suranal bem distintas.

Espiráculos abdominais de A1-A7 circulares e menores que os pares $\mathrm{T} 1 \mathrm{e}$ A8 que são semelhantes e apresentam a forma elíptica. Os ganchos dos larvópodos possuem a cor castanho e a disposição é unisserial biordinal.

O tegumento do tórax e abdome nas áreas dorsal, subdorsal, supraespiracular até a linha dos espiráculos apresenta ornamentações castanhas contornando a base dos escolos e formando linhas transversais descontínuas, no final de cada segmento. Áreas subespiracular e ventral amarelo leitoso predominante com pigmentação castanha acentuada no tórax. Pequenas cerdas hialinas distribuídas por todo o tegumento.

Mensurações. Largura da cápsula cefálica, obtida através da distância entre os lados externos do terceiro par de estemas $(\mathrm{n}=44)$ : variando de 0,8 a $1,06 \mathrm{~mm}$. Comprimento total $(\mathrm{n}=5)$ : variando de 0,61 a $0,68 \mathrm{~cm}$.

\section{Larva de quarto instar}

Cabeça. Com mesmo padrão e coloração das larvas de segundo instar.

Corpo. Larvas com o padrão mais escuro, apresentam os escolos dorsais do tórax, abdominais A1, A8, A9 e supraespiraculares de A 10 castanhos com espinhos castanho claros; todos os escolos subespiraculares castanho amarelados com espinhos hialinos castanho claros e o restante dos escolos castanho amarelados com o ápice castanho e espinhos castanho claros.

As larvas com o padrão mais claro apresentam os escolos dorsais de T1, T2, A9 e supraespiracular de A10 castanhos com espinhos castanho claros, os demais são castanho amarelados com espinhos hialinos castanho claros. Além destes há outros padrões intermediários de coloração. Placas pronotal e suranal bem distintas.

Espiráculos abdominais de A1-A7 circulares e menores que os de T1 e A8 que são semelhantes e apresentam a forma elíptica. Ganchos dos larvópodos com disposição unisserial biordinal. 
O tegumento do tórax e abdome apresenta padrão semelhante ao do terceiro instar, porém a faixa castanha é mais evidente sobre a linha dos escolos supraespiraculares. Pequenas cerdas hialinas distribuídas por todo o tegumento.

Mensurações. Largura da cápsula cefálica, obtida através da distância entre os lados externos do terceiro par de estemas $(\mathrm{n}=32)$ : variando de 1,16 a $1,48 \mathrm{~mm}$. Comprimento total $(\mathrm{n}=5)$ : variando de 0,92 a $1,12 \mathrm{~cm}$.

\section{Larva de quinto instar}

Cabeça. Com mesmo padrão de coloração dos ínstares anteriores, exceto pela sutura epicranial branco-amarelada.

Corpo. As larvas com padrão mais escuro, apresentam todos os escolos dorsais, supraespiraculares e laterais castanhos com espinhos variando do castanho claro ao hialino; os escolos subespiraculares castanho amarelados com espinhos hialinos castanho claros.

Nas larvas com padrão mais claro apenas os escolos dorsais de T1, T2 e A9 e supraespiracular de A10 castanhos com espinhos castanho claros, os demais castanho amarelados com espinhos variando do castanho claro ao hialino. Além destes há outros padrões intermediários de coloração. Placas pronotal e suranal de castanho intenso.

Espiráculos apresentam a forma elíptica, T1 e A8 são semelhantes e maiores que os demais. Ganchos dos larvópodos com disposição unisserial biordinal.

Tegumento do tórax e abdome semelhante ao quarto instar. Pequenas cerdas hialinas estão distribuídas por todo o tegumento.

Mensurações. Largura da cápsula cefálica, obtida através da distância entre os lados externos do terceiro par de estemas $(n=47)$ : variando de 1,6 a $2,08 \mathrm{~mm}$. Comprimento total da larva $(\mathrm{n}=5)$ : variando de 1,28 a $1,43 \mathrm{~cm}$.

\section{Larva de sexto instar}

Cabeça. Com mesmo padrão de coloração do instar anterior.

Corpo. Larvas mais escuras seguem o padrão das do quinto instar.

As larvas mais claras apresentam os escolos dorsais do tórax, dorsais abdominais de $\mathrm{A}$ 1-A3 e A7-A9, supraespiraculares e laterais castanhos com espinhos variando do castanho claro ao hialino; os escolos dorsais de A4-A6 e os subespiraculares castanho-amarelados com espinhos hialinos castanho-claros. Além destes há outros padrões intermediários de coloração. Placas pronotal e suranal bem distintas.

Espiráculos apresentam a forma elíptica, os pares T1 e A8 são semelhantes e maiores que os demais. Os ganchos dos larvópodos possuem a cor castanho e a disposição é unisserial biordinal.

Tegumento do tórax e abdome semelhante ao do quinto instar, com duas faixas, uma mais escura com ornamentações de tons de castanho na área dorsal e supraespiracular até a linha dos espiráculos, e outra amarelo-leitosa predominante na região subespiracular e ventral. Pequenas cerdas hialinas estão distribuídas por todo o tegumento.

Mensurações. Largura da cápsula cefálica, obtida através da distância entre os lados externos do terceiro par de estemas $(\mathrm{n}=42)$ : variando de 2,04 a $2,6 \mathrm{~mm}$. Comprimento total $(\mathrm{n}=7)$ : variando de 1,66 a $1,9 \mathrm{~cm}$. 


\section{Larva de sétimo instar (Figs 12-13)}

Cabeça. Com mesmo padrão de coloração do instar anterior.

Corpo. Mesmo padrão das larvas mais escuras do sexto instar, exceto pelos escolos dorsais de A4-A6 branco acinzentados ou mesclados com castanho, porém se tornam evidentes três bandas na área dorsal e supraespiracular; uma anterior e outra posterior de cor castanho alaranjado com fundo castanho enegrecido e a mediana, branco acinzentado com fundo enegrecido. As cores marrom alaranjado e branco acizentado contornam a base dos escolos e formam linhas descontinuas na região terminal de cada segmento. A banda anterior ocupa geralmente os segmentos de T1-A3, a mediana de A4-A6 e a posterior de A7-A 10; os espinhos dos escolos são castanho claros, branco acinzentados e castanho claros acompanhando as respectivas bandas. $\mathrm{Na}$ área subespiracular e ventral predomina o amarelo leitoso. Pequenas cerdas castanho claro hialinas estão distribuídas por todo o tegumento do corpo. Placas pronotal e suranal distintas.

Espiráculos de forma elíptica, os pares T1 e A8 são semelhantes e maiores que os demais. Placas laterais dos larvópodos castanho amareladas de A3-A6 e castanho escura em A10. Ganchos dos larvópodos castanho com disposição unisserial biordinal.

Mensurações. Largura da cápsula cefálica, obtida através da distância entre os lados externos do terceiro par de estemas $(n=22)$ : variando de 2,32 a $3,52 \mathrm{~mm}$. Comprimento total $(\mathrm{n}=6)$ : variando de 2,73 a $3,05 \mathrm{~cm}$.

\section{Pupa (Figs 14-16)}

Branco amarelada com faixas abdominais: ventral, laterais e dorso-laterais castanho-escuras; preenchendo o contorno das tecas alares, gáleas e antenas, castanho claro. Algumas pupas podem apresentar esta ornamentação em tom de castanho acentuadamente mais claro, variação presente tanto em machos como em fêmeas. Minúsculas cerdas, imperceptíveis a olho nu, pouco mais escuras que o tegumento, distribuídas na cabeça, nos escleritos dos olhos, frontoclípeo, vértice e no corpo, exceto nas tecas alares, pernas, antenas e gáleas. Protuberância acentuada entre 0 frontoclípeo e os olhos. As estruturas da cabeça e do tórax com o contorno castanho-escuro e em alguns pontos castanho claro nitidamente reconhecíveis. Pro, meso e metanoto com um par de projeções simétricas, que decrescem de tamanho em direção ao metanoto, na cor branco amarelado como o restante do tegumento. Tecas alares, com projeções laterais na base. Espiráculos de A2 encobertos parcialmente pelas tecas alares. De A2 até A6, seguindo a mesma linha de distribuição das projeções do tórax, encontram-se cinco pares de espinhos, látero-dorsais, castanhoescuros, sem ramificações ou cerdas. Os espinhos de A2 são 2/3 do tamanho do restante dos espinhos, estes praticamente iguais e, estão nas faixas dorso-laterais, castanho-escuras. Cremaster formado pelas regiões ventral de A9 e dorsal e ventral de A10, totalmente modificadas em uma estrutura escura de aspecto corrugado e com cerdas.

A eclosão dos adultos (Figs 17-18) ocorreu de onze a treze dias após o empupamento. 

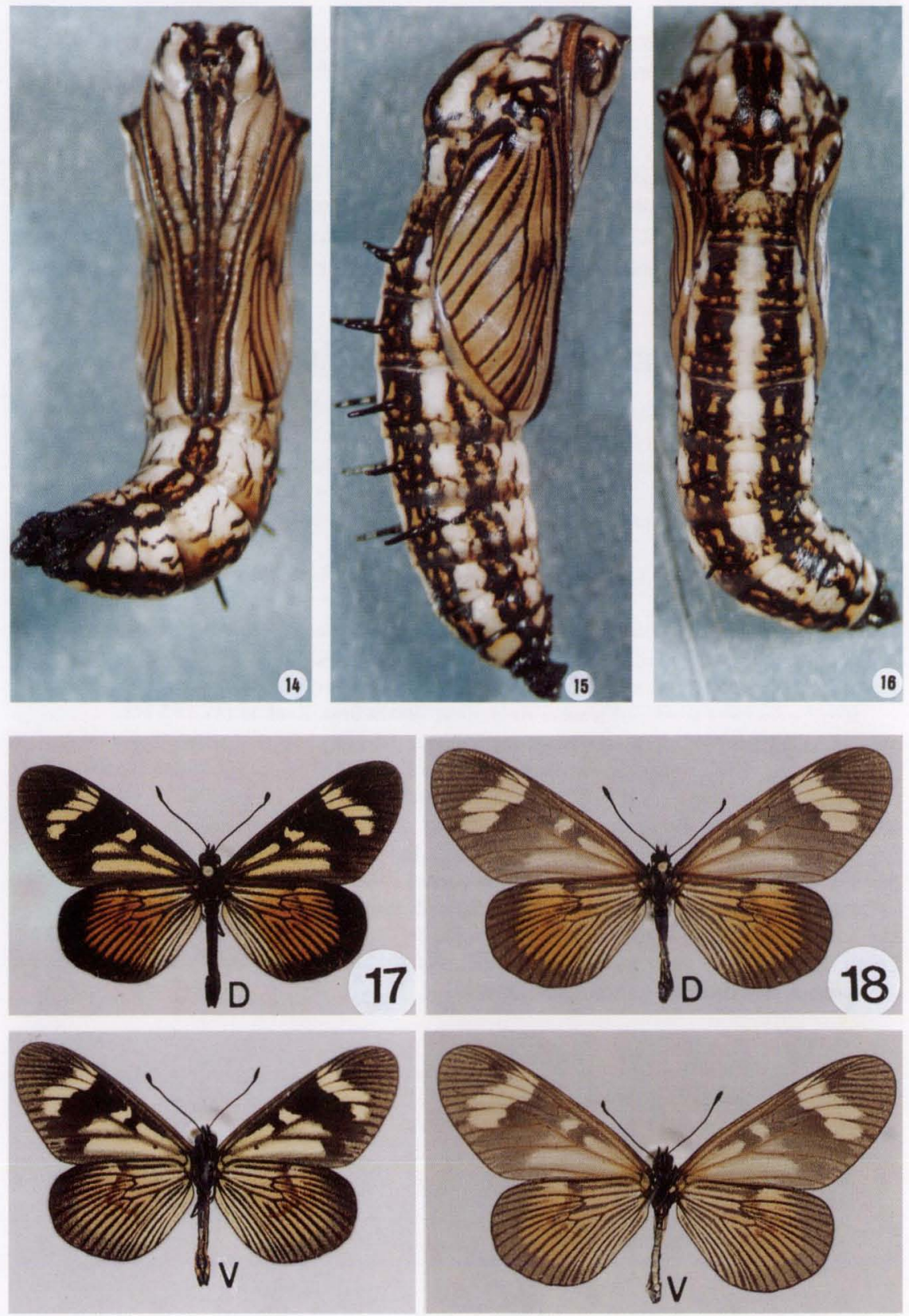

Figs 14-18. Actinote carycina. (14-16) Pupa: (14) vista anterior; (15) vista posterior; (16) vista lateral; (17-18) Adulto: (17) macho; (18) fêmea. (d) Vista dorsal, (v) vista ventral. 


\section{Parasitóide}

Baseado em material coletado no campo em Curitiba, Paraná, foi identificado Lespesia plaumanni Guimarães, 1983 (Diptera, Tachinidae, Eryciini) parasitando larvas.

AGRADECIMENTOS. Ao Dr. Ronaldo Toma do Museu de Zoologia, Universidade de São Paulo, pela identificação do parasitóide. Ao Dr. Maurício Pereira Cantão do Laboratório Central de Pesquisa e Desenvolvimento Convênio COPEL/UFPR, pela ajuda nas sessões de microscopia eletrônica de varredura. Aos amigos MSc. Marcelo Duarte e MSc. Jorge M.S. Bizarro pelas informações e sugestões.

\section{REFERÊNCIAS BIBLIOGRÁFICAS}

BiezANKo, C.M.; A. Rufinelli \& D. Link. 1974. Plantas y otras substancias alimenticias de las orugas de los lepidopteros Urugayos. Rev. Centro Ci. Rurais, Santa Maria, 4 (2): 107-148.

Brown, K.S. 1992. Borboletas da Serra do Japi: diversidade, habitats, recursos alimentares e variação temporal, p. 142-186. In: Morellato, L.P.C. (Ed.). História natural da Serra do Japi. Ecologia e preservação de uma área florestal no sudeste do Brasil. Campinas, Ed. Unicamp, Fapesp, Brasil, $321 \mathrm{p}$.

D'Almeida, R.F. 1935. Les Actinote de la partie orientale de L' Amérique du Sud. Ann. Acad. Bras. Sc. 7 (1): 71-112.

HiNTON, H.E. 1946. On the homology and nomenclature of the setae of lepidopteran larvae, with some notes on the phylogeny of the Lepidoptera. Trans. R. Ent. Soc. Lond. 97: 1-37.

Mielke, C.G.C. 1994. Papilionoidea e Hesperioidea (Lepidoptera) de Curitiba e seus arredores, Paraná, Brasil, com notas taxonômicas sobre Hesperiidae. Revta bras. Zool. 11 (4): 737-748.

Mielke, O.H.H. \& M.M. Casagrande. 1986. Sobre os tipos de Lepidoptera depositados em museus brasileiros. III - Nymphalidae (Danaine, Brassolinae, Morphinae, Satyrinae, Nymphalinae e Acraeinae), descritos por R.F. D'Almeida. Revta bras. Ent. 30 (1): 141-152.

Paluch, M.; M.M. Casagrande \& O.H.H. Mielke. 1999. Estágios imaturos de Actinote surima (Schaus) (Lepidoptera, Nymphalidae, Acraeinae). Revta bras. Zool. 16 (Supl. 2): 129-140.

PETERSON, A. 1962. Larvae of Insects. An Introduction to Neartic Species. Part I. Lepidoptera and Plant Infesting Hymenoptera. Michigan, Edwards Brothers Inc. Ann Arbor, 315p.

STEHR, F.W. 1987. Immature Insects. Dubuque, Kendall Hunt, Vol. 1, XII+754p.

ZIKÁN, J.F. 1952. Wie gross ist die Nachkommenschaft bei Lepidopteren, Coleopteren, Mantiden und Orthopteren? Dusenia, Curitiba, 3 (4): 289-302.

Recebido em 23.XI.2000; aceito em 27.VIII.2001. 